\title{
Lung cancer incidence in patients with schizophrenia: meta-analysis
}

\author{
Chuanjun Zhuo, Hongqing Zhuang, Xiangyang Gao and Patrick Todd Triplett
}

\section{Background}

Lung cancer risk factors, like tobacco smoking, are highly prevalent in patients with schizophrenia. Whether these patients have a higher risk of lung cancer remains unknown.

\section{Aims}

We aimed to investigate whether patients with schizophrenia have a higher incidence of lung cancer compared with general population, in a meta-analysis

\section{Method}

Eligible studies were searched from PubMed and EMBASE databases to identify cases of lung cancer in patients with schizophrenia and the general population. This meta-analysis utilised the random-effects model and prediction interval was used to calculate the heterogeneity of these eligible studies. We assessed the quality of evidence with the Grading of Recommendations Assessment, Development and Evaluation (GRADE) approach.

\section{Results}

There were 12 studies, totalling 496265 patients, included in this meta-analysis. The data showed that the baseline schizophrenia diagnosis was not associated with any changes in lung cancer incidence in the overall population, with a standardised incidence ratio of 1.11 (95\% $\mathrm{Cl} 0.90-1.37 ; P=0.31)$, although there was a significant heterogeneity among these studies $\left(I^{2}=94 \%\right)$.
Moreover, there was also a substantial between-study variance with wide prediction interval values $(0.47-2.64)$. The data were consistent for both males and females.

\section{Conclusions}

Up-to-date evidence from epidemiological studies indicates the lack of certainty about the association between schizophrenia diagnosis and lung cancer incidence.

\section{Declaration of interest}

None.

\section{Keywords}

Schizophrenia; lung cancer risk; cancer incidence; metaanalysis.

\section{Copyright and usage}

(C) The Royal College of Psychiatrists 2019. This is an Open Access article, distributed under the terms of the Creative Commons Attribution-NonCommercial-NoDerivatives licence (http://creativecommons.org/licenses/by-nc-nd/4.0/), which permits noncommercial re-use, distribution, and reproduction in any medium, provided the original work is unaltered and is properly cited. The written permission of Cambridge University Press must be obtained for commercial re-use or in order to create a derivative work.
Lung cancer is a significant health problem worldwide, accounting for $1,800,000$ new lung cancer cases or $13 \%$ of newly diagnosed cancers globally in 2012. ${ }^{1}$ Tobacco smoke is a single most significant risk factor in developing lung cancer, ${ }^{1}$ although whether patients with schizophrenia have a higher risk of lung cancer remains unknown. Previous studies showed a higher prevalence of tobacco smoking and higher risk of lung cancer in patients with schizophrenia than in the general population. ${ }^{2-4}$ However, results of a previous meta-analysis did not support this notion, showing that the risk of lung cancer incidence was higher than the general population. ${ }^{5}$ Indeed, a previous genetic study reported that differences in $p 53$ polymorphisms might be responsible for the genetic association between patients with schizophrenia and a potentially reduced risk of lung cancer, ${ }^{6}$ which further complicates the association between schizophrenia and lung cancer risk. However, results of previous cohort studies are inconclusive; that is, some studies have suggested that patients with schizophrenia have an increased risk of lung cancer, ${ }^{7,8}$ whereas other studies have not. ${ }^{9-18}$ Additionally, many updated analyses have been published since the previous meta-analysis, highlighting the importance of an updated meta-analysis. For example, previous meta-analyses were performed on the basis of a heterogeneity evaluation, using a conventional statistic, namely $I^{2}$. The use of $I^{2}$ as the sole heterogeneity index has been questioned, whereas the prediction interval has been encouraged to analyse the heterogeneity index in a random-effects meta-analysis. ${ }^{19}$ Thus, in this study, we performed a meta-analysis to stratify the potential influence of tobacco smoking on lung cancer risk for patients with schizophrenia.

\section{Method}

\section{Literature search}

In this study, we searched PubMed and EMBASE databases to identify eligible studies of patients with lung cancer in both the schizophrenia and general populations. The search terms used were 'schizophrenia', 'schizophrenic', 'psychosis', 'psychoses', 'psychotic $^{*}$ or 'schizo ${ }^{*}$ in combination with 'lung', and 'cancer', 'tumor', 'neoplasm' or 'carcinoma'. Two of our investigators independently searched the databases and reviewed each of publications. Any discrepancies were discussed and solved by the third investigator together with the two investigators. Kappa was calculated to reflect the interrater reliability for study inclusion/exclusion in the revised manuscript. Studies included in this meta-analysis were restricted to human studies and those published in English. Moreover, we also performed a manual search for cited reference lists in the original and review articles. The last literature search was performed on 26 June 2018.

\section{Inclusion and exclusion criteria}

Studies were included if they fulfilled all of the following criteria: (a) prospective or retrospective cohort studies without restrictions to the sample size and follow-up duration, and published in English as a full-length article; (b) enrolled adult participants $(\geq 18$ years of age); (c) schizophrenia was defined as the exposure of interest at baseline; (d) general population without schizophrenia were 
defined as a control; (e) reported lung cancer incidence during follow-up and (f) reported lung cancer incidence with adjusted standardised incidence ratios (SIRs), adjusted by age and gender at least, and the corresponding 95\% confidence intervals of patients with schizophrenia relative to the general population.

Schizophrenia and lung cancer were diagnosed according to the criteria applied in all original articles. If a study included any overlapping participants, we only used the one with the larger sample sizes. Furthermore, our study only included the incidence study to avoid potential difference in outcome of lung cancer-related mortality between treatment of patients with schizophrenia and the general population.

\section{Data extraction and quality evaluation}

The following data were extracted from each study: (a) the first author name, publication years and patients' country of origin; (b) number of patients with schizophrenia at baseline and the source of the study populations; (c) follow-up durations, cases of lung cancer during follow-up and the methods applied for the identification of lung cancer cases and (d) other characteristics, such as whether tobacco smoking was adjusted when reporting the SIR outcome or whether lung cancer diagnosis was made before schizophrenia diagnosis (if this was yes, the study or participant were excluded). This meta-analysis utilised the NewcastleOttawa Scale for quality evaluation, according to a previous study. ${ }^{20}$ This scale ranges from 1 to 9 stars, including criteria based on three aspects: selection of a study group, the comparability of the groups and the confirmation of the outcome. Moreover, we used the Grading of Recommendations Assessment, Development and Evaluation (GRADE) approach to assess the quality of the body of evidence. ${ }^{21}$ The GRADE methodology involves rating the initial quality of evidence for an association as high (with observational data), followed by downgrading based on five criteria (risk of bias, inconsistency, imprecision, indirectness and publication bias), and upgrading based on three criteria (large effect size, dose-response gradient, and plausible confounding). Abstracts, letters, reviews, noncohort studies and those reporting mortality data rather than incidence data were excluded from this meta-analysis.

\section{Statistical analyses}

This meta-analysis utilised the SIR as the overall measurement of the association between baseline schizophrenia and lung cancer risk for patients across all included studies. The most adequately adjusted data were then extracted and the logarithmically transformed SIRs and their corresponding s.e. were computed. Moreover, for heterogeneity evaluation, Cochrane's $Q$-test ${ }^{22}$ and the $I^{2}$ statistic $^{23}$ were performed and we defined the significant heterogeneity as $I^{2}>50 \%$. The random-effects model was applied to combine the SIR data because this model is considered to have a more generalised result as it incorporates the potential heterogeneity. ${ }^{24}$ In addition, we calculated the prediction interval based on the method provided by Borenstein et al, which was the range that the true SIR of a future study may fall in $95 \%$ of populations. ${ }^{19} \mathrm{We}$ also performed sensitivity analyses by removing studies one at a time, to evaluate the stability of the results. Next, we utilised the predefined subgroup analyses to determine whether study characteristics that could significantly affect our data analyses and results, such as the exclusion of lung cancer incidence before schizophrenia diagnosis. We evaluated the potential publication bias by funnel plots supplemented by the Egger regression asymmetry test. ${ }^{25}$ All statistical analyses were performed with RevMan version 5.1 (Cochrane Collaboration, Oxford, UK: https://community.cochrane.org/help/tools-and-software/revman-5) and Stata version 12.0 for Windows (Stata Corporation, College Station, TX).

\section{Results}

\section{Identified studies for the meta-analysis}

In this study, we searched PubMed and EMBASE databases to identify eligible studies, and the data are shown in Supplementary Figure 1 available at https://doi.org/10.1192/bjp.2019.23. In brief, we initially identified a total of 912 studies, and 881 were excluded after reviewing the titles and abstracts. We obtained 31 relevant articles for full-text review, and a further 19 articles were excluded for the following reasons: two of studies analysed patients with other mental diseases, two were duplicated reports, six were without the available outcome of lung cancer incidence, six were with mortality data only and two did not include the outcome of lung cancer incidence as the SIR. Thus, we were left with 12 studies for this metaanalysis. $^{7-18}$ The Kappa for the interrater reliability of the process of study inclusion/exclusion was 0.89 .

\section{Study characteristics and quality evaluation}

This meta-analysis included 12 studies $^{7-18}$ totalling 496265 patients with schizophrenia, and their baseline data are summarised in Table 1. All of these studies were retrospective database studies, including participants from the USA, ${ }^{8}$ Asia, ${ }^{10,13,14,16,18}$ Australia $^{9}$ and Europe. ${ }^{7,11,12,15,17}$ Some of the studies included only mental health centre in-patients with schizophrenia, ${ }^{7,11,12,15}$ whereas other studies included patients with schizophrenia without specifying the setting. ${ }^{8-10,13,14,16-18}$ The inclusion and the follow-up durations spanned from 1962 to 2011. A total of 2151 lung cancer cases were diagnosed during the follow-up of patients with schizophrenia. Moreover, all studies reported the SIR of lung cancer incidence comparing patients with schizophrenia with the general population from the same country, during similar follow-up durations; however, there were only eight studies providing the SIR data separately in men and women. $8,9,11,12,14-16,18$ Only one study adjusted for tobacco smoking when presenting the SIR data, ${ }^{26}$ and in seven studies, the investigators clearly stated that only lung cancer incidence after schizophrenia diagnosis was evaluated., ${ }^{9,11,13-17}$ The Newcastle-Ottawa scores ranged from 6 to 8 for the included cohort studies and all of the included studies were database-based cohort studies. Patients with a confirmed diagnosis of schizophrenia were included, and the general population without schizophrenia were selected as controls. The follow-up durations of the included studies were between 10 and 29 years, which was adequate. However, given the large sample sizes and the registry-based nature of the included studies, poor sample controls regarding the diagnosis of schizophrenia, baseline characteristic evaluation and diagnosis of lung cancer were likely to exist. Moreover, confounding factors, such as smoking was adjusted in only one of the included studies. Following the GRADE methodology, we graded the quality of evidence for the outcome incidence of lung cancer' to very low because risk of bias of inconsistency, indirectness and imprecision may exist (Supplementary Table 1).

\section{Schizophrenia and lung cancer risk in the overall populations}

When combining the results from the 12 studies, ${ }^{7-18}$ our metaanalysis data showed that, compared with the general population from the same countries, patients with schizophrenia at baseline were not significantly associated with lung cancer risk ( $\mathrm{SIR}=1.11$, 95\% CI 0.90-1.37, $P=0.31$; Fig. 1a), although there was a significant heterogeneity $\left(P<0.01\right.$ by Cochrane's $Q$-test, $\left.I^{2}=94 \%\right)$ and a wide prediction interval $(0.47-2.64)$ was detected. The data indicated an existence of substantial variance among these 12 studies. However, following the GRADE methodology, the quality of evidence was very low (Supplementary Table 1). 


\begin{tabular}{|c|c|c|c|c|c|c|c|c|c|c|c|c|}
\hline Author, year & Country & $\begin{array}{l}\text { Patient } \\
\text { characteristics }\end{array}$ & $\begin{array}{l}\text { Number of } \\
\text { patients with } \\
\text { schizophrenia }\end{array}$ & $\begin{array}{l}\text { Comparison } \\
\text { population }\end{array}$ & $\begin{array}{l}\text { Follow-up } \\
\text { (years) }\end{array}$ & $\begin{array}{l}\text { Confirmation of } \\
\text { lung cancer cases }\end{array}$ & $\begin{array}{l}\text { Number of } \\
\text { lung cancer } \\
\text { cases }\end{array}$ & $\begin{array}{l}\text { SIR } \\
\text { outcomes } \\
\text { reported }\end{array}$ & $\begin{array}{l}\text { Smoking } \\
\text { adjusted }\end{array}$ & $\begin{array}{l}\text { Exclusion of cancer } \\
\text { incidence before } \\
\text { schizophrenia }\end{array}$ & $\begin{array}{l}\text { Quality } \\
\text { score }\end{array}$ & SIR $(95 \% \mathrm{Cl})$ \\
\hline $\begin{array}{l}\text { Lawrence, } \\
2000^{9}\end{array}$ & Australia & $\begin{array}{l}\text { Patients of mental health } \\
\text { services }\end{array}$ & 172932 & $\begin{array}{l}\text { General western } \\
\text { Australian } \\
\text { population }\end{array}$ & 1966-1995 & ICD-9 classification ${ }^{27}$ & 856 & $M, F$ & N & Y & 8 & $\begin{array}{l}\text { M: } 1.10(0.96-1.30) ; \\
F: 1.10(0.91-1.30)\end{array}$ \\
\hline $\begin{array}{l}\text { Lichtermann, } \\
\quad 2001^{7}\end{array}$ & Finland & $\begin{array}{l}\text { In-patients or those with } \\
\text { disability pension for } \\
\text { schizophrenia }\end{array}$ & 26996 & $\begin{array}{l}\text { General Finnish } \\
\text { population }\end{array}$ & 1971-1996 & Finnish Cancer Registry & 106 & T & N & NS & 7 & $2.17(1.78-2.60)$ \\
\hline $\begin{array}{l}\text { Goldacre, } \\
2005^{12}\end{array}$ & UK & $\begin{array}{l}\text { In-patients with } \\
\text { schizophrenia in Oxford }\end{array}$ & 9649 & General population & 1963-1999 & $\begin{array}{l}\text { National Health Service } \\
\text { data }\end{array}$ & 88 & T & N & NS & 6 & $1.18(0.94-1.45)$ \\
\hline Barak, $2005^{10}$ & Israel & $\begin{array}{l}\text { Patients at a mental health } \\
\text { centre }\end{array}$ & 3226 & $\begin{array}{l}\text { General population } \\
\text { of Israel }\end{array}$ & 1993-2003 & $\begin{array}{l}\text { National Cancer } \\
\quad \text { Registry of Israel }\end{array}$ & 9 & $\mathrm{~T}$ & N & NS & 6 & $0.65(0.29-1.23)$ \\
\hline Dalton $2005^{11}$ & Denmark & $\begin{array}{l}\text { In-patients with } \\
\text { schizophrenia }\end{array}$ & 22766 & $\begin{array}{l}\text { General Danish } \\
\text { population }\end{array}$ & 1969-1995 & Danish Cancer Registry & 147 & $M, F$ & $\mathrm{~N}$ & Y & 8 & $\begin{array}{l}\text { M: } 0.82(0.65-1.02) ; \\
\text { F: } 1.17(0.90-1.49)\end{array}$ \\
\hline $\begin{array}{l}\text { Grinshpoon, } \\
2005^{13}\end{array}$ & Israel & $\begin{array}{l}\text { Patients diagnosed with } \\
\text { schizophrenia }\end{array}$ & 26518 & $\begin{array}{l}\text { General population } \\
\text { of Israel }\end{array}$ & 1962-2001 & $\begin{array}{l}\text { National Cancer } \\
\text { Registry of Israel }\end{array}$ & 126 & $\mathrm{M}, \mathrm{F}$ & N & Y & 8 & $\begin{array}{l}\text { M: } 1.38(1.11-1.65) ; \\
\text { F: } 0.85 \text { (0.50-1.19) }\end{array}$ \\
\hline Chou, $2011^{14}$ & China & $\begin{array}{l}\text { Patients diagnosed with } \\
\text { schizophrenia in } \\
\text { National Health } \\
\text { Insurance Research } \\
\text { Database }\end{array}$ & 59257 & $\begin{array}{l}\text { Age- and gender- } \\
\text { matched } \\
\text { individuals }\end{array}$ & 2000-2008 & ICD-9 classification & 96 & $M, F, T$ & N & Y & 8 & $0.55(0.44-0.69)$ \\
\hline McGinty, $2012^{8}$ & USA & $\begin{array}{l}\text { Patients diagnosed with } \\
\text { schizophrenia }\end{array}$ & 2315 & $\begin{array}{l}\text { General population } \\
\text { from the national } \\
\text { database }\end{array}$ & 1994-2004 & $\begin{array}{l}\text { Data based on } \\
\text { Surveillance } \\
\text { Epidemiology and } \\
\text { End Results } \\
\text { Database }\end{array}$ & 28 & $M, F, T$ & $\mathrm{~N}$ & NS & 6 & $4.70(3.10-6.80)$ \\
\hline Lin, $2013^{16}$ & China & $\begin{array}{l}\text { Patients diagnosed with } \\
\text { schizophrenia }\end{array}$ & 102202 & $\begin{array}{l}\text { General population } \\
\text { from the health } \\
\text { insurance } \\
\text { database }\end{array}$ & 1995 2007 & $\begin{array}{l}\text { National Cancer } \\
\text { Database }\end{array}$ & 144 & $M, F, T$ & $\mathrm{~N}$ & Y & 8 & $0.81(0.77-0.96)$ \\
\hline $\mathrm{Ji}, 2013^{15}$ & Sweden & $\begin{array}{l}\text { In-patients with } \\
\text { schizophrenia }\end{array}$ & 59233 & $\begin{array}{l}\text { General Swedish } \\
\text { population }\end{array}$ & 1965-2008 & $\begin{array}{l}\text { National Cancer } \\
\text { Registry of Sweden }\end{array}$ & 451 & $\mathrm{M}, \mathrm{F}, \mathrm{T}$ & $\mathrm{N}$ & Y & 8 & $0.75(0.68-0.82)$ \\
\hline Osborn, $2013^{17}$ & UK & $\begin{array}{l}\text { Patients diagnosed with } \\
\text { schizophrenia }\end{array}$ & 6845 & $\begin{array}{l}\text { Age, gender, GP and } \\
\text { calendar time } \\
\text { matched } \\
\text { controls }\end{array}$ & 1990-2008 & $\begin{array}{l}\text { Medical record- } \\
\text { confirmed cases }\end{array}$ & 67 & $\mathrm{~T}$ & Y & Y & 8 & $0.95(0.65-1.41)$ \\
\hline Raviv, $2014^{18}$ & Israel & $\begin{array}{l}\text { Male patients of a mental } \\
\text { health centre }\end{array}$ & 4326 & $\begin{array}{l}\text { General population } \\
\text { of Israel }\end{array}$ & 1990-2011 & $\begin{array}{l}\text { National Cancer } \\
\text { Registry of Israel }\end{array}$ & 33 & $\mathrm{~T}, \mathrm{M}$ & $\mathrm{N}$ & NS & 6 & $1.43(0.98-2.01)$ \\
\hline
\end{tabular}


(a)

\begin{tabular}{lrrcc} 
Study or subgroup & log(SIR) & \multicolumn{1}{c}{ s.e. } & Weight & $\begin{array}{c}\text { SIR } \\
\text { IV, Random, 95\% Cl }\end{array}$ \\
\hline Lawrence 2000-M & 0.0953 & 0.0773 & $7.3 \%$ & $1.10(0.95-1.28)$ \\
Lawrence 2000-F & 0.0953 & 0.091 & $7.2 \%$ & $1.10(0.92-1.31)$ \\
Lichtermann 2001 & 0.7747 & 0.0967 & $7.2 \%$ & $2.17(1.80-2.62)$ \\
Goldacre 2005 & 0.1655 & 0.1106 & $7.1 \%$ & $1.18(0.95-1.47)$ \\
Barak 2005 & -0.4308 & 0.3686 & $4.0 \%$ & $0.65(0.32-1.34)$ \\
Dalton 2005-M & -0.1985 & 0.1149 & $7.0 \%$ & $0.82(0.65-1.03)$ \\
Dalton 2005-F & 0.157 & 0.1286 & $6.9 \%$ & $1.17(0.91-1.51)$ \\
Grinshpoon 2005-M & 0.3221 & 0.1011 & $7.2 \%$ & $1.38(1.13-1.68)$ \\
Grinshpoon 2005-F & -0.1625 & 0.2212 & $5.8 \%$ & $0.85(0.55-1.31)$ \\
Chou 2011 & -0.5978 & 0.1148 & $7.0 \%$ & $0.55(0.44-0.69)$ \\
McGinty 2012 & 1.5476 & 0.2004 & $6.0 \%$ & $4.70(3.17-6.96)$ \\
Lin 2013 & -0.2107 & 0.0563 & $7.5 \%$ & $0.81(0.73-0.90)$ \\
Ji 2013 & -0.2877 & 0.0478 & $7.5 \%$ & $0.75(0.68-0.82)$ \\
Osborn 2013 & -0.0513 & 0.1975 & $6.1 \%$ & $0.95(0.65-1.40)$ \\
Raviv 2014 & 0.3577 & 0.1832 & $6.2 \%$ & $1.43(1.00-2.05)$ \\
& & & & $1.11(0.90-1.37)$ \\
Total (95\% Cl) & & & $100.0 \%$ & \\
Heterogeneity: Tau ${ }^{2}=0.15 ; X^{2}=225.12$, d.f. $=14(P<0.00001) ;$ & $I^{2}=94 \%$ \\
Test for Overall effect: Z $=1.01(P=0.31)$ &
\end{tabular}

(b)

\begin{tabular}{lrrrc} 
Study or subgroup & $\log (\mathrm{SIR})$ & \multicolumn{1}{c}{ s.e. } & Weight & $\begin{array}{c}\text { SIR } \\
\text { IV, Random, 95\% Cl }\end{array}$ \\
\hline Lawrence 2000-M & 0.0953 & 0.0773 & $11.3 \%$ & $1.10(0.95-1.28)$ \\
Lawrence 2000-F & 0.0953 & 0.091 & $10.9 \%$ & $1.10(0.92-1.31)$ \\
Dalton 2005-M & -0.1985 & 0.1149 & $10.1 \%$ & $0.82(0.65-1.03)$ \\
Dalton 2005-F & 0.157 & 0.1286 & $9.6 \%$ & $1.17(0.91-1.51)$ \\
Grinshpoon 2005-M & 0.3221 & 0.1011 & $10.5 \%$ & $1.38(1.13-1.68)$ \\
Grinshpoon 2005-F & -0.1625 & 0.2212 & $6.5 \%$ & $0.85(0.55-1.31)$ \\
Chou 2011 & -0.5978 & 0.1148 & $10.1 \%$ & $0.55(0.44-0.69)$ \\
Lin 2013 & -0.2107 & 0.0563 & $11.8 \%$ & $0.81(0.73-0.90)$ \\
Ji 2013 & -0.2877 & 0.0478 & $12.0 \%$ & $0.75(0.68-0.82)$ \\
Osborn 2013 & -0.0513 & 0.1975 & $7.2 \%$ & $0.95(0.65-1.40)$ \\
& & & & \\
Total (95\% Cl) & & $100.0 \%$ & $0.92(0.78-1.08)$ \\
Heterogeneity: Tau ${ }^{2}=0.05 ; X^{2}=69.64$, d.f. $=9(P<0.00001) ; I^{2}=87 \%$ \\
Test for Overall effect: $Z=1.03(P=0.30)$
\end{tabular}

Test for overall effect: $Z=1.03(P=0.30)$

SIR

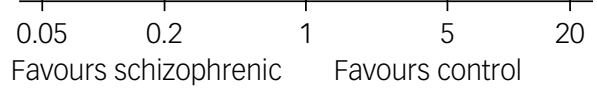

SIR
SIR

IV, Random, 95\% Cl

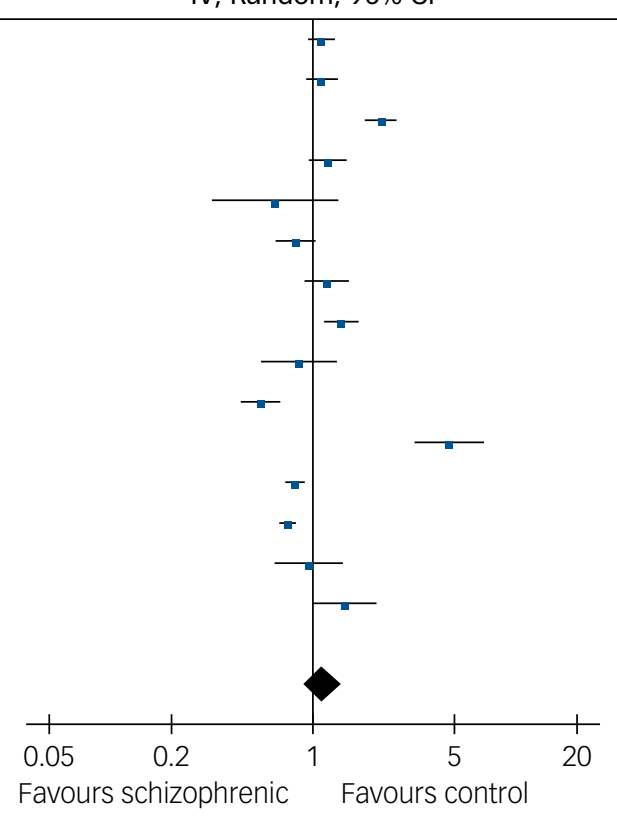

IV, Random, 95\% Cl

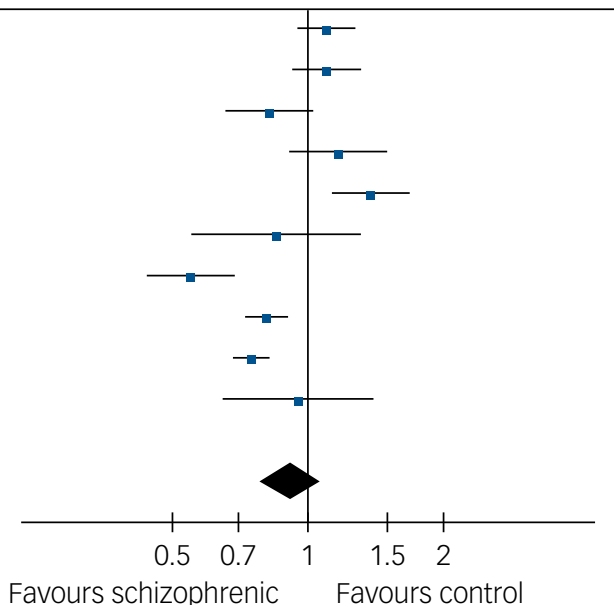

Favours schizophrenic Favours control

Fig. 1 Forest plots for the meta-analysis of the association between schizophrenia and lung cancer risk. (a) Forest plots of the overall population in this meta-analysis for association of schizophrenia with risk of developing lung cancer. (b) Forest plots of studies excluding patients with lung cancer diagnosed before the diagnosis of schizophrenia.

SIR, standardised incidence ratio; IV, inverse variance.

Overall, our findings suggest that the up-to-date evidence from epidemiological studies indicates the lack of certainty about the association between schizophrenia diagnosis and lung cancer incidence. Future studies may show significantly affected lung cancer risk in patients with schizophrenia compared with the general population. Indeed, the results of our sensitivity analyses excluding one study at a time also did not significantly alter the pooled results (data not shown), suggesting good robustness of the study. Subsequent analyses of studies by excluding patients with lung cancer diagnosis before schizophrenia diagnosis ${ }^{9,11,13-17}$ produced similar results (SIR=0.92, 95\% CI $0.78-1.08, P=0.30$; Fig. 1b), with significant heterogeneity $\left(P<0.01\right.$ by Cochrane's $Q$-test, $I^{2}=$ $87 \%$; prediction interval: $0.53-1.60)$. The only study that adjusted tobacco smoke status when presenting the results did not support a significantly affected lung cancer incidence in patients with schizophrenia (SIR=0.95, 95\% CI 0.65-1.40).

\section{Schizophrenia and lung cancer risk stratified by gender}

We then separately evaluated the risk of lung cancer in male and female patients with schizophrenia. By pooling the data from eight studies with SIR data on male patients with schizophrenia, ${ }^{8,9,11,13-16,18}$ our meta-analysis showed that a baseline diagnosis of schizophrenia did not significantly affect the risk of male lung cancer incidence (SIR=1.03, 95\% CI 0.78-1.35, $P=0.86$; Fig. 2a), although there was substantial heterogeneity $(P<0.01$ by Cochrane's $Q$-test, $I^{2}=93 \%$; prediction interval: $\left.0.39-2.73\right)$. We found that exclusion of participants with a lung cancer diagnosis before a schizophrenia diagnosis also had similar results (SIR $=0.83,95 \%$ CI $0.64-1.07, P=0.15$; Fig. $2 b$ ), although significant heterogeneity also occurred $\left(P<0.01\right.$ by Cochrane's $Q$-test, $I^{2}=$ 92\%; prediction interval: $0.34-2.06)$. Similarly, after pooling the results of seven studies that provided data on female patients with 
(a)

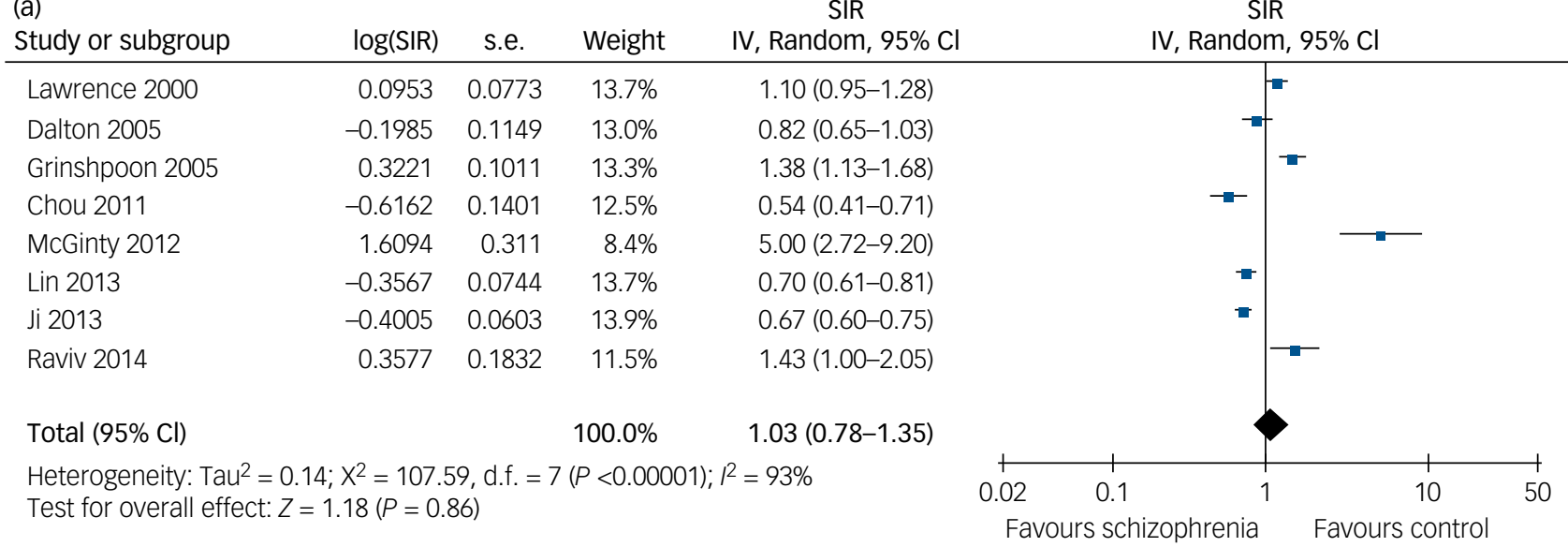

(b)

\begin{tabular}{lcccc} 
Study or subgroup & $\log (\mathrm{SIR})$ & s.e. & Weight & IV, Random, 95\% C \\
\hline Lawrence 2000 & 0.0953 & 0.0773 & $17.3 \%$ & $1.10(0.95-1.28)$ \\
Dalton 2005 & -0.1985 & 0.1149 & $16.1 \%$ & $0.82(0.65-1.03)$ \\
Grinshpoon 2005 & -0.3221 & 0.1011 & $16.5 \%$ & $1.38(1.13-1.68)$ \\
Chou 2011 & -0.6162 & 0.1401 & $15.1 \%$ & $0.54(0.41-0.71)$ \\
Lin 2013 & -0.3567 & 0.0744 & $17.3 \%$ & $0.70(0.61-0.81)$ \\
Ji 2013 & -0.4005 & 0.0603 & $17.7 \%$ & $0.67(0.60-0.75)$ \\
& & & \\
Total (95\% Cl) & & $100.0 \%$ & $0.83(0.64-1.07)$ \\
Heterogeneity: Tau $2=0.09 ; X^{2}=65.56$, d.f. $=5(P<0.00001) ; I^{2}=92 \%$ \\
Test for Overall effect: $Z=1.45(P=0.15)$
\end{tabular}

Fig. 2 Forest plots for the meta-analysis of the association between schizophrenia and lung cancer risk in males. (a) Forest plots of male patients in this meta-analysis for association of schizophrenia with risk of developing lung cancer. (b) Forest plots of studies excluding male patients with lung cancer diagnosed before the diagnosis of schizophrenia.

SIR, standardised incidence ratio; IV, inverse variance.

schizophrenia, ${ }^{8,9,11,13-16}$ our meta-analysis showed that a baseline diagnosis of schizophrenia did not significantly affect the risk of female lung cancer incidence (SIR=1.10, 95\% CI 0.85-1.41, $P=$ 0.47; Fig. 3a), although substantial heterogeneity existed $(P<0.01$ by Cochrane's $Q$-test, $I^{2}=87 \%$; prediction interval: $0.48-2.54$ ). After excluded participants with lung cancer diagnosis before schizophrenia diagnosis, the data were also similar $(\mathrm{SIR}=0.96$, 95\% CI 0.82-1.11, $P=0.55$; Fig. 3b), although there was significant heterogeneity among these original studies $(P=0.02$ by Cochrane's $Q$-test, $I^{2}=62 \%$; prediction interval: $\left.0.58-1.43\right)$.

\section{Publication bias}

We performed a funnel plot to assess publication bias and the data are shown in Supplementary Figure 2. We found that the funnel plot was visually symmetric and that the data on the Egger regression test indicated no significant publication bias occurring in these studies $(P=0.466)$.

\section{Discussion}

In the current study, based on the findings from previous databasederived, retrospective cohort studies, we failed to indicate a certain association between schizophrenia diagnosis and lung cancer incidence. Considerable heterogeneity exists regarding the included cohort, and the quality of the evidence of the meta-analysis was downgraded because of the potential risk of bias in inconsistency, indirectness and imprecision. Subsequent analyses demonstrated that our data were consistent in men and women, although there was significant heterogeneity underlying the pooled results of the overall population, as well as male and female participants.

Because many cancer-related risk factors, such as tobacco smoke, physical inactivity, obesity or metabolic disorders, ${ }^{2,4,5}$ have been shown to be prevalent in patients with schizophrenia, it has been speculated that patients with schizophrenia have an increased risk of developing many illnesses, including cancer. However, there are also studies that suggest that patients with schizophrenia may have a lower risk of cancer. The possible protective effect of schizophrenia on cancer incidence has been proposed after some early epidemiological studies showing that cancer incidence in the siblings and parents of patients with schizophrenia were lower than that in the general population. ${ }^{7}$ A previous meta-analysis showed that patients with schizophrenia had the same overall cancer incidence as the general populations, and that their the siblings and parents had even lower overall cancer incidence than that of the general populations. ${ }^{5}$ A previous meta-analysis showed that patients with schizophrenia had a slightly higher risk of lung cancer incidence ( $\mathrm{SIR}=1.31,95 \%$ CI 1.01-1.71), but this previous study revealed that such results could be insignificant after adjusting for prevalence of tobacco smoke. ${ }^{5}$ In updating the previous meta-analysis, our current data showed that schizophrenia did not affect lung cancer incidence despite the fact that many lung cancer risk factors were prevalent in this population. These findings raise the possibility 
(a)

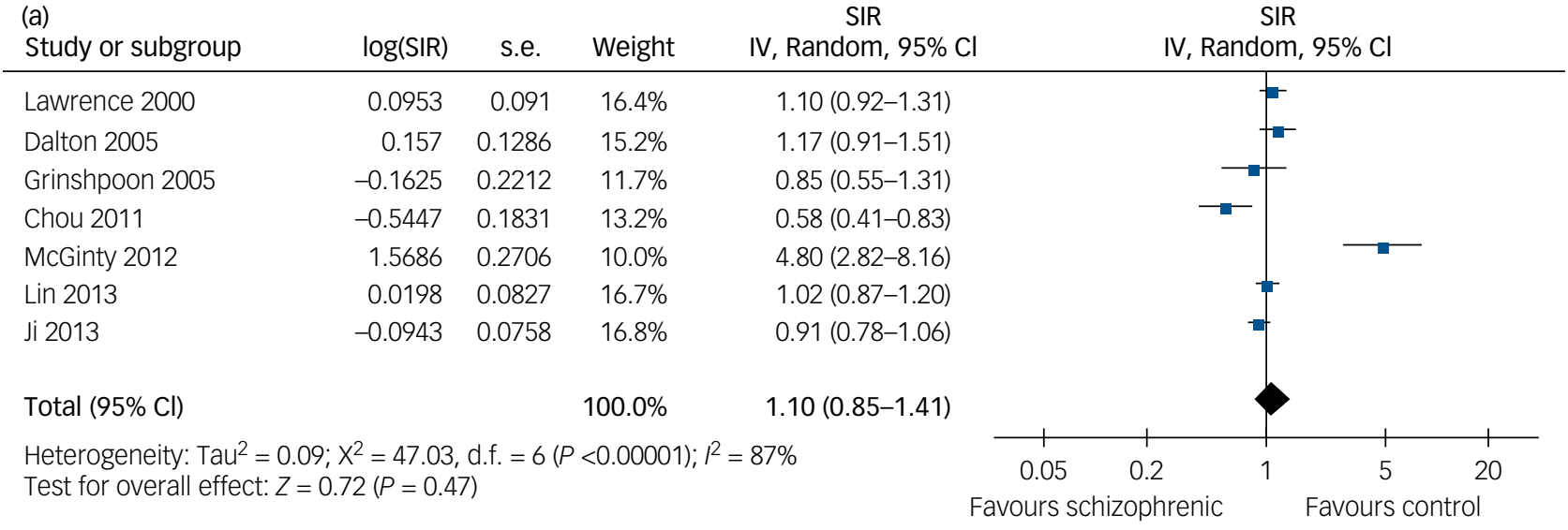

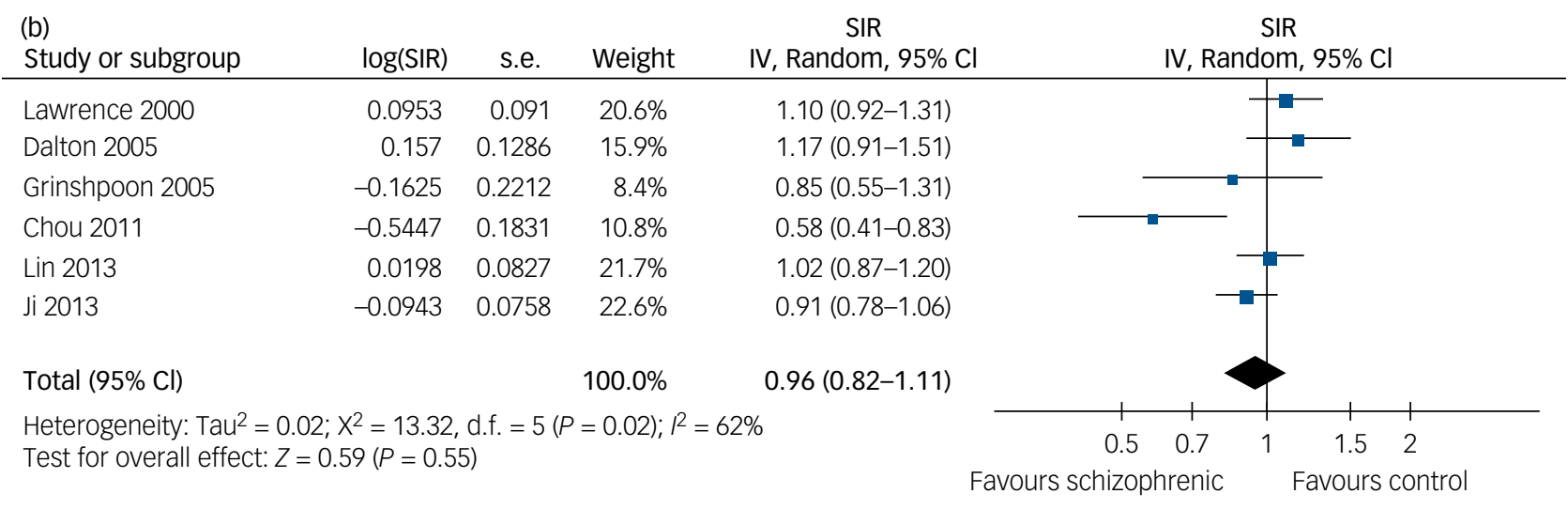

Fig. 3 Forest plots for the meta-analysis of the association between schizophrenia and lung cancer risk in females. (a) Forest plots of female patients in this meta-analysis for association of schizophrenia with risk of developing lung cancer. (b) Forest plots of studies excluding female patients with lung cancer diagnosed before the diagnosis of schizophrenia.

SIR, standardised incidence ratio; IV, inverse variance.

that schizophrenia may provide protective effects from cancer on a genetic level. Further, a previous review examined repurposing of psychiatric drugs as anti-cancer agents, ${ }^{26}$ and some recent genetic studies also provided further clues for this phenomenon. For example, a previous study of Chinese patients with schizophrenia showed that genetic variants of XRCC4, which more often occurs in patients with schizophrenia, might have protective effects against colorectal cancer. ${ }^{28}$ Subsequent studies proposed that microRNA 183 could also be a protective factor against solid tumours in patients with schizophrenia. ${ }^{29}$ However, other studies reported shared genetic variants between schizophrenia and lung cancer, and patients with schizophrenia had a higher prevalence of tobacco use than general populations because of loss of nicotinic receptor expression, ${ }^{30,31}$ suggesting the complexity of the genetic influence of schizophrenia on cancer incidence. Thus, further study of cancer incidence in patients with mental illness may help us to stratify lung cancer risk factors.

Furthermore, we also calculated the prediction interval to evaluate the heterogeneity for the random effects in this meta-analysis, which should be acknowledged as a strength of our current study. Accordingly, our current data showed a considerably high between-study variance (prediction interval: 0.47-2.64), indicating that lung cancer incidence could be found to be significantly changed (either increased or decreased) in future studies comparing patients with schizophrenia with the general population. Indeed, in light of the variable quality of the included studies, the considerable heterogeneity of the meta-analysis and the wide prediction interval, the results of our study may reflect an uncertainty of the current understanding between schizophrenia and risk of lung cancer based on the findings of epidemiological studies. From this perspective, the results of our current study highlight a limitation of epidemiological studies on association of schizophrenia with lung cancer risk because of a considerable heterogeneity among these studies. With the development of methodologies in big-data research, including deep neural network analysis, the potential associations of schizophrenia with cancer risk may be better stratified according to biological functional or genetic levels. Future studies are warranted in these fields.

\section{Limitations and future directions}

Our study does have some limitations; for example, as mentioned in a previous meta-analysis, ${ }^{5}$ each original study might not have adjusted the lung cancer-related risk factors (like tobacco smoking) and in this case, analysis of association between schizophrenia and lung cancer risks could have confounded results. Moreover, these confounding factors remain, including body mass index, occupational information and dietary habits, and may affect association of schizophrenia with lung cancer risk. Thus, we recommend that future studies provide detailed information regarding the prevalence of associated risk factors in patients with schizophrenia and controls. In addition, our study showed a significant heterogeneity among these original studies, such as different diagnostic criteria used for schizophrenia and lung cancer, different schizophrenia treatment regimens and different methodologies to confirm lung cancer diagnosis, all of which need to be solved in 
future studies. Additionally, we only included studies from PubMed and EMBASE and did not include studies from other databases, those not in English or those published as conference abstracts. However, including studies from PubMed and EMBASE may have covered the majority of available literature. In addition, including conference abstracts that did not undergo peer review may potentially cause other bias. Moreover, given the large sample sizes and the registry-based nature of the included studies, poor sample controls regarding the diagnosis of schizophrenia, baseline characteristic evaluation and diagnosis of lung cancer were likely to be present in the individual cohort studies, which may weaken the validity of the comparison in this meta-analysis. Finally, our study only focused on the outcome of lung cancer incidence regardless of the histopathology of lung cancer. It is unknown whether schizophrenia contributed to incidence of small-cell or non-small-cell lung cancer incidence, which needs more precise study in future.

Overall, our current meta-analysis sheds lights on future directions in clarifying the potential association and underlying mechanisms between schizophrenia and lung cancer risk. First, studies are needed to determine whether the risk factors of lung cancer, such as tobacco smoking, obesity, substance misuse and diabetes, are potential confounding factors for the association between schizophrenia and lung cancer risk. Second, there are not many studies on the genetics and biology underlying the associations of schizophrenia with lung cancer risk. Thus, more studies are needed to elucidate the association between schizophrenia and lung cancer risk. Third, it also needs to be determined whether other characteristics in patients with schizophrenia, such as the use of antipsychotic medications, variability in patient management and disease course, or discrepancies in identifying lung cancer cases, further compound the heterogeneity of previous cohort studies. Finally, the influence of smoking on the general health status in patients with schizophrenia deserves further evaluation. Although the prevalence of tobacco smoking was significantly higher in patients with schizophrenia (approximately $80 \%$ ) than that of the general population, results of our study indicated that the lung cancer risk was not higher in patients with schizophrenia. ${ }^{31}$ Also, smoking in schizophrenia has been hypothesized as 'self-treatment' because it may normalise sensory processing deficits in patients with schizophrenia. ${ }^{30}$ Nonetheless, smoking cessation should still be encouraged in patients with schizophrenia, as no protective effect from schizophrenia on lung cancer risk has been definitively been proven, and smoking may expose these patients to risk for other smoking-related malignancies. Moreover, from a clinical perspective, smoking may lower the plasma level of antipsychotics such as clozapine, thereby hampering the treatment efficacy of these antipsychotics. ${ }^{32}$

In conclusion, the up-to-date evidence from epidemiological studies indicates the lack of certainty about the association between schizophrenia diagnosis and lung cancer incidence. Because of the large heterogeneity of previously published cohort studies, the association between schizophrenia and lung cancer risk should be determined by further studies based on genetic and biological functional associations. These contradictory studies have prompted us to perform relevant research to investigate the mechanisms of low lung cancer incidence in smokers with schizophrenia from multiple perspectives.

Chuanjun Zhuo, MD, PhD (D), Professor, Department of Psychiatric-NeuroimagingGenetics Laboratory, Tianjin Anding Hospital; Department of Psychiatry and Comorbidity, Mental Health Teaching Hospital, Tianiin Medical University; Department of Psychiatry, Hospital, China; Hongqing Zhuang, MD, Professor, Department of Radiation Oncology, Hospital, China; Hongqing Zhuang, MD, Professor, Department of Radiation Oncology
Peking University Third Hospital, China; Xiangyang Gao, PhD, Professor, Health Peking University Third Hospital, China; Xiangyang Gao, PhD, Professor, Health Patrick Todd Triplett, MD, PhD, Assistant Professor, Department of Psychiatry and Behavioral Sciences, Johns Hopkins School of Medicine, USA
Correspondence: Chuanjun Zhuo, Department of Psychiatry and Comorbidity, Mental Health Teaching Hospital, Tianjin Medical University, 13 Liulin Road, Hexi District, Tianjin 300300, China. Email: chuanjunzhuotjmh@163.com

First received 18 May 2018, final revision 7 Oct 2018, accepted 11 Jan 2019

\section{Supplementary material}

Supplementary material is available online at https://doi.org/10.1192/bjp.2019.23.

\section{Funding}

This work was supported by grants from the Tianjin Health Bureau Foundation (2014KR02 to C Z ) and the Key Projects of the Natural Science Foundation of Tianjin, China (17JCZDJC35700 to C.Z.).

\section{Acknowledgements}

The authors would like to thank Prof. Andrea Cipriani, Department of Psychiatry, University of Oxford, UK, for his valuable help in methodologies used in this study and revision of this manuscript. Authors C.Z., H.Z., and X.G. had full access to all the data in the study and take the responsibility for the integrity of the data and the accuracy of the data analysis.

\section{References}

1 Torre LA, Bray F, Siegel RL, Ferlay J, Lortet-Tieulent J, Jemal A. Global cancer statistics, 2012. CA Cancer J Clin 2015; 65: 87-108.

2 Li Q, Du X, Zhang Y, Yin G, Zhang G, Walss-Bass C, et al. The prevalence, risk factors and clinical correlates of obesity in Chinese patients with schizophrenia. Psychiatry Res 2017; 251: 131-6.

3 Miyauchi M, Kishida I, Suda A, Shiraishi Y, Fujibayashi M, Taguri M, et al. Long term effects of smoking cessation in hospitalized schizophrenia patients. BMC Psychiatry 2017; 17: 87

4 Morris A. Diabetes: linking diabetes and schizophrenia. Nat Rev Endocrinol 2017; 13: 126

5 Catts VS, Catts SV, O'Toole BI, Frost AD. Cancer incidence in patients with schizophrenia and their first-degree relatives - a meta-analysis. Acta Psychiatr Scand 2008; 117: 323-36.

6 Ozbey U, Yuce H, Namli M, Elkiran T. Investigation of differences in P53 gene polymorphisms between schizophrenia and lung cancer patients in the Turkish population. Genet Res Int 2011; 2011: 483851.

7 Lichtermann D, Ekelund J, Pukkala E, Tanskanen A, Lonnqvist J. Incidence of cancer among persons with schizophrenia and their relatives. Arch Gen Psychiatry 2001; 58: 573-8.

8 McGinty EE, Zhang Y, Guallar E, Ford DE, Steinwachs D, Dixon LB, et al. Cancer incidence in a sample of Maryland residents with serious mental illness. Psychiatr Serv 2012; 63: 714-7.

9 Lawrence D, Holman CD, Jablensky AV, Threlfall TJ, Fuller SA. Excess cancer mortality in Western Australian psychiatric patients due to higher case fatality rates. Acta Psychiatr Scand 2000; 101: 382-8.

10 Barak Y, Achiron A, Mandel M, Mirecki I, Aizenberg D. Reduced cancer incidence among patients with schizophrenia. Cancer 2005; 104: 2817-21.

11 Dalton SO, Mellemkjaer L, Thomassen L, Mortensen PB, Johansen C. Risk for cancer in a cohort of patients hospitalized for schizophrenia in Denmark, 19691993. Schizophr Res 2005; 75: 315-24.

12 Goldacre MJ, Kurina LM, Wotton CJ, Yeates D, Seagroat V. Schizophrenia and cancer: an epidemiological study. Br J Psychiatry 2005; 187: 334-8.

13 Grinshpoon A, Barchana M, Ponizovsky A, Lipshitz I, Nahon D, Tal O, et al. Cancer in schizophrenia: is the risk higher or lower? Schizophr Res 2005; 73: 333-41.

$14 \mathrm{Chou} \mathrm{FH}$, Tsai KY, Su CY, Lee CC. The incidence and relative risk factors for developing cancer among patients with schizophrenia: a nine-year follow-up study. Schizophr Res 2011; 129: 97-103.

15 Ji J, Sundquist K, Ning Y, Kendler KS, Sundquist J, Chen X. Incidence of cance in patients with schizophrenia and their first-degree relatives: a populationbased study in Sweden. Schizophr Bull 2013; 39: 527-36.

16 Lin $\mathrm{CY}$, Lane HY, Chen $\Pi$, Wu YH, Wu CY, Wu VY. Inverse association between cancer risks and age in schizophrenic patients: a 12-year nationwide cohort study. Cancer Sci 2013; 104: 383-90.

17 Osborn DP, Limburg H, Walters K, Petersen I, King M, Green J, et al. Relative incidence of common cancers in people with severe mental illness. Cohort 
study in the United Kingdom THIN primary care database. Schizophr Res 2013; 143: 44-9.

18 Raviv G, Laufer M, Baruch Y, Barak Y. Risk of prostate cancer in patients with schizophrenia. Compr Psychiatry 2014; 55: 1639-42.

19 Borenstein M, Higgins JP, Hedges LV, Rothstein HR. Basics of meta-analysis: I(2) is not an absolute measure of heterogeneity. Res Synth Methods 2017; 8: 5-18.

20 Wells GA, Shea B, O'Connell D, Peterson J, welch V, Losos M, et al. The Newcastle-Ottawa Scale (NOS) for Assessing the Quality of Nonrandomised Studies in Meta-Analyses. Ottawa Hospital Research Institute, 2010 (http:// www.ohri.ca/programs/clinical_epidemiology/oxford.asp).

21 Iorio A, Spencer FA, Falavigna M, Alba C, Lang E, Burnand B, et al. Use of GRADE for assessment of evidence about prognosis: rating confidence in estimates of event rates in broad categories of patients. BMJ 2015; 350: h870.

22 Higgins J, Green S. Cochrane Handbook for Systematic Reviews of Interventions Version 5.1.0. The Cochrane Collaboration, 2011 (www. cochranehandbook.org)

23 Higgins JP, Thompson SG. Quantifying heterogeneity in a meta-analysis. Stat Med 2002; 21: 1539-58.

24 Patsopoulos NA, Evangelou E, loannidis JP. Sensitivity of between-study heterogeneity in meta-analysis: proposed metrics and empirical evaluation. Int J Epidemiol 2008; 37: 1148-57.

25 Egger M, Davey Smith G, Schneider M, Minder C. Bias in meta-analysis detected by a simple, graphical test. BMJ 1997; 315: 629-34.

26 Huang J, Zhao D, Liu Z, Liu F. Repurposing psychiatric drugs as anti-cancer agents. Cancer Lett 2018; 419: 257-65.

27 Torgersen T, Rosseland LA, Malt UF. Coding guidelines for ICD-9 section on mental disorders and reliability of chart clinical diagnoses. Acta Psychiatr Scand. 1990; 81(1): 62-7.

28 Wang Y, Wang L, Li X, Liu B, Zhao Q, Chen P, et al. Polymorphisms of XRCC4 are involved in reduced colorectal cancer risk in Chinese schizophrenia patients. BMC Cancer 2010; 10: 523.

29 Rizos E, Siafakas N, Koumarianou A, Katsantoni E, Filippopoulou A, Ntounas P, et al. miR-183 as a molecular and protective biomarker for cancer in schizophrenic subjects. Oncol Rep 2012; 28: 2200-4.

30 Zuber V, Jonsson EG, Frei O, Witoelar A, Thompson WK, Schork AJ, et al. Identification of shared genetic variants between schizophrenia and lung cancer. Sci Rep 2018; 8: 674.

31 Leonard S, Adams CE. Smoking cessation and schizophrenia. Am J Psychiatry 2006; 163: 1877

32 Huang HC, Lua AC, Wu LS, Wu BJ, Lee SM, Liu CZ. Cigarette smoking has a differential effect on the plasma level of clozapine in Taiwanese schizophrenic patients associated with the CYP1A2 gene -163A/C single nucleotide polymorphism. Psychiatr Genet 2016; 26: 172-7. 